\title{
POSSIBILITY OF USING ELECTRIC POWER STORAGE SYSTEMS IN RURAL REGIONS WITH COMBIBATION OF RENEWABLE ENERGY SOURCES FOR AUTONOMOUS ENERGY SUPPLY
}

\author{
Vladislav Zavadskiy ${ }^{1}$, Gita Revalde ${ }^{2}$ \\ ${ }^{1}$ Almaty University of Power Engineering and Telecommunication, Kazakhstan; \\ ${ }^{2}$ Riga Technical University, Latvia \\ vladislav.zavadskiy@gmail.com, gita.revalde@rtu.lv
}

\begin{abstract}
The paper presents a developed method for modelling of the possibilities of autonomous electrical energy system operation in remote or rural places including power storage systems and renewable energy sources. The methodology includes analyzing of the potential for renewable energy sources. The energy, produced from the RES can be characterized as variable generation (VG) and this creates certain difficulties for the involvement of RES in the overall generation. Another point is that there can be limited possibilities of the links to the electrical grid in rural regions. There are several options of solving such problem, like: back up power supply with diesel generators and etc. One of the most promising solutions to this problem is creation of power storage facilities. The main purpose of the power storage facility is to smooth out the peaks of electricity generation and consumption. The second purpose is to provide power supply in the case of absence of generation from renewables. The numerical results show the possibilities of autonomous operation of a part of the power system with a certain combination of renewable energy sources and electric power storage, and covering the electricity deficit from the renewables instead of commissioning of traditional energy sources. We show that solving the problem of power supply and cover the electricity deficit in rural places with the help of renewable energy, including power storage systems, can minimize the impact on the environment in rural regions.
\end{abstract}

Keywords: autonomous power supply, renewable energy sources, electric power storage systems, rural regions.

\section{Introduction}

The task of the power industry is to provide uninterrupted power supply to consumers. Agriculture is no exception. However, in contrast to urban areas, agricultural facilities may be located in very distant regions. Therefore, with the power supply of these regions there are certain features.

Also, there has been a trend towards decentralization of power supply [1]. With the growing demand for electricity and the increasingly acute problems of energy shortages in remote areas, as well as environmental problems, the disadvantages of traditional electricity production are becoming increasingly noticeable [2]. As a result, countries around the world have introduced policies that encourage companies to optimize their energy mix, promote energy conservation and reduce emissions, and achieve sustainable economic development. In this new situation distributed energy resources are actively developing. This allows a more flexible approach to environmental issues, more efficiently carry out the production of heat and electricity and solve issues related to the flexibility of the power system $[3,4]$.

This paper presents modelling of the remote part of the network on the example of Kazakhstan to proof the possibility of its autonomous operation. Simulation was based on using the general approach of solving the unit commitment (UC) problem with usage of the renewable energy sources [5].

On the example of power supply to remote rural consumers in the region of Mangystau, Kazakhstan will be shown the possibility of working part of the power system autonomously, using electricity storage facilities.

\section{Materials and methods}

The energy, produced from the RES can be characterized as variable generation (VG) and as already mentioned, this creates certain difficulties for the involvement of RES in the overall generation. One of the solutions to this problem is the creation of power storage facilities. The main purpose of the power storage facility is to smooth out the peaks of electricity generation and consumption. That is why a lot of types of storage technologies are being developed and implemented during the past decades with different characteristics, Table 1 [6].

Such facilities seem expensive, but the price for storage energy installations continuously goes down, Figure 1 [7]. 
Characteristics of various types of electricity storage facilities

Table 1

\begin{tabular}{|c|c|c|c|c|c|}
\hline Conversion & Storage type & EUR $\cdot(k W h)^{-1}$ & EUR $\cdot(k W h)^{-1}$ & Cycles (100 \%) & Efficiency \\
\hline \multirow{4}{*}{ Mechanica1 } & $\begin{array}{c}\text { Supercapacito } \\
r\end{array}$ & $3,800-4,000$ & $100-400$ & $10,000-100,000$ & $95-100 \%$ \\
\hline & Flywhee1s & $1,000-3,000$ & 300 & $20,000-60,000$ & $90-95 \%$ \\
\hline & Pumped Hydro & $60-150$ & 500 & $20,000-50,000$ & $70-85 \%$ \\
\hline & $\begin{array}{l}\text { Compressed } \\
\text { Air }\end{array}$ & $30-120$ & 550 & $9,000-20,000$ & $70-80 \%$ \\
\hline \multirow{7}{*}{$\begin{array}{l}\text { Electro- } \\
\text { chemical }\end{array}$} & $\begin{array}{c}\text { Nicke1-metal } \\
\text { hydride }\end{array}$ & $700-800$ & - & $500-3,000$ & $65 \%$ \\
\hline & $\begin{array}{l}\text { Nicke1- } \\
\text { Cadmium }\end{array}$ & $350-800$ & 175 & $1,000-3,000$ & $60-70 \%$ \\
\hline & Sodium-Sulfur & $200-900$ & 150 & $2,000-3,000$ & $85-90 \%$ \\
\hline & Lithium-Ion & $200-500$ & 175 & $3,000-6,000$ & $95-100 \%$ \\
\hline & $\begin{array}{l}\text { Vanadium } \\
\text { Redox-Flow }\end{array}$ & $100-1,000$ & 175 & $2,000-3,000$ & $75-85 \%$ \\
\hline & Zinc-Bromine & $50-400$ & 175 & $>2,000$ & $70 \%$ \\
\hline & Zinc-Bromine & $50-300$ & 175 & $200-1,100$ & $75 \%$ \\
\hline
\end{tabular}

The average price for stored energy for consumers nowadays is about 300-500 USD.(MWh) ${ }^{-1}$. The lowest price is $190 \mathrm{USD} \cdot(\mathrm{MWh})^{-1}$ [8]. So, in the simulation a central large-scale stationary battery with endogenous capacity and conversion efficiency factor $75 \%$ with the price of storage energy of 190 USD.(MWh) ${ }^{-1}$ will be considered. Therefore, to cover the peaks of electricity fluctuations, the installed capacity of the storage should be $25 \%$ greater than its nominal capacity. To calculate the nominal capacity of the electric power storage, it is proposed to use and approbate it in the model of the method, which can be expressed by the formula

$$
P_{s}=P_{d R E S \max }-P_{d R E S \text { min }}
$$

where $P_{s}-$ nominal power of the storage unit;

$P_{d R E S \max }$ - daily maximum power output from RES;

$P_{d R E S \min }$ - daily minimum power output from RES.

According to the analysis for the region, the most relevant is the use of wind and solar energy [5]. To simulate the process of UC with combined production of solar and wind energy, it is necessary to find the optimal fraction of generation of solar and wind energy. To do this, it is necessary to analyze the generation of wind and solar energy in the proposed location of the installation for a certain period. For the purposes of this study a period of one year is taken. Using the Renewables.ninja [9] tool, the following data was obtained, which are presented in Figures 2, 3. 


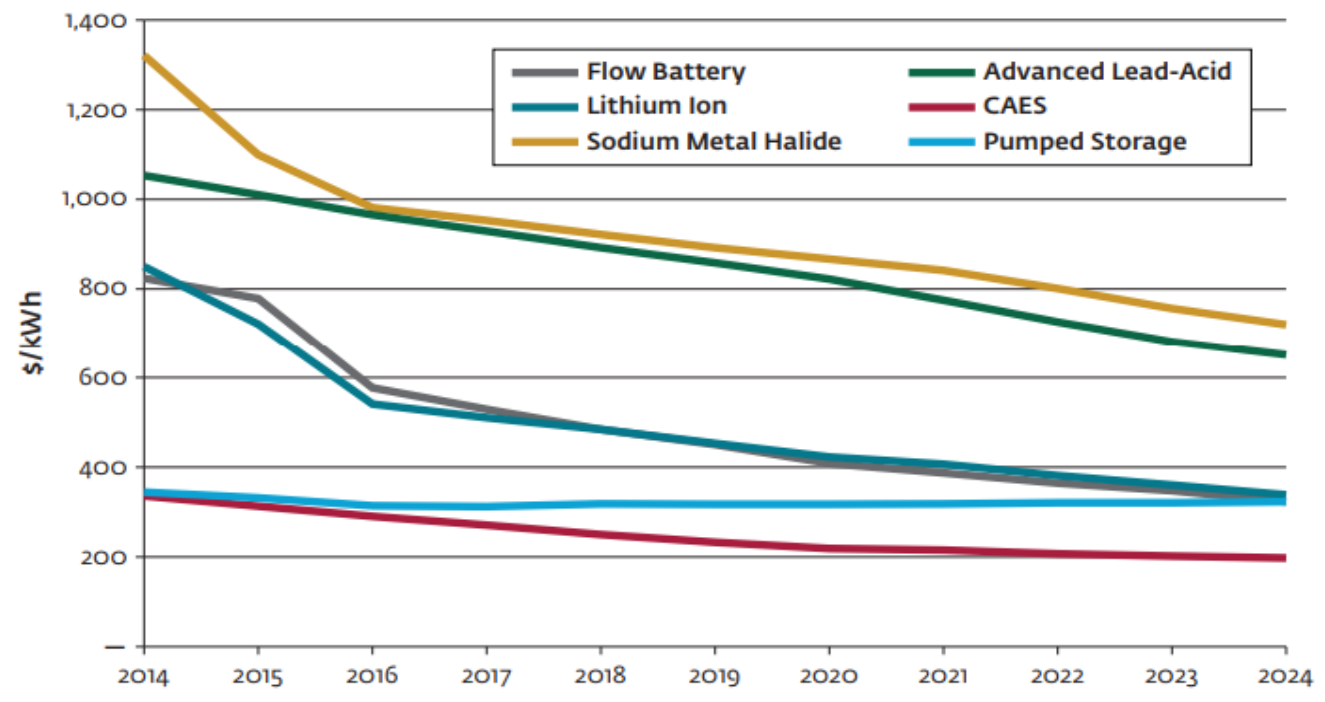

Fig. 1. Storage energy facilities systems installation price trends by year

Renewables.ninja allows to run simulations of the hourly power output from wind and solar power plants located anywhere in the world. It was built to help make scientific-quality weather and energy data available to a wider community. [9] The table (Table 2.) gives the same data given in relative units.

Table 2

12 months power generation profiles from the wind and PV solar plant sources simulation in the Mangistau region for the year 2014

\begin{tabular}{|c|c|c|c|c|c|c|c|c|c|c|c|c|}
\hline Months & $\mathbf{1}$ & $\mathbf{2}$ & $\mathbf{3}$ & $\mathbf{4}$ & $\mathbf{5}$ & $\mathbf{6}$ & $\mathbf{7}$ & $\mathbf{8}$ & $\mathbf{9}$ & $\mathbf{1 0}$ & $\mathbf{1 1}$ & $\mathbf{1 2}$ \\
\hline $\begin{array}{c}\text { Wind, Relative } \\
\text { units }\end{array}$ & 0.2858 & 0.3521 & 0.3795 & 0.3467 & 0.2689 & 0.2546 & 0.1604 & 0.1779 & 0.301 & 0.2143 & 0.3198 & 0.3779 \\
\hline $\begin{array}{c}\text { Solar, Relative } \\
\text { units }\end{array}$ & 0.0975 & 0.1618 & 0.2016 & 0.2159 & 0.2376 & 0.2292 & 0.2272 & 0.2165 & 0.1781 & 0.1742 & 0.1129 & 0.0922 \\
\hline
\end{tabular}
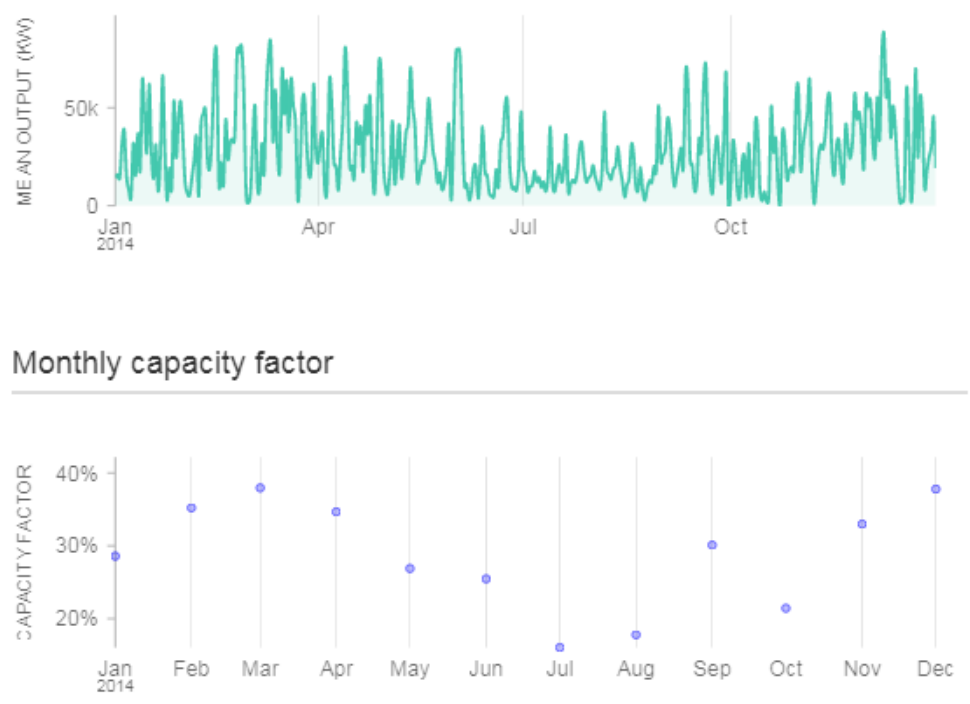

Total mean capacity factor: $28.6 \%$

Fig. 2. Renewables.ninja $100 \mathrm{MW}$ wind farm power output profile simulation for 2014

The solution of this problem can be represented as a solution to the problem of nonlinear optimization (NLP). There are many mathematical methods for solving such problems. According to the studies [10], one of the most suitable methods is the Generalized Reduced Gradient Method 
(GRG). The basic idea of the GRG method can be explained as a linearizing the non-linear objective and constraint functions at a local solution with Taylor expansion equation. Then, the concept of reduced gradient method is employed, which divides the variable set into two subsets of basic and non-basic variables and the concept of implicit variable elimination to express the basic variable by the non-basic variable. Finally, the constraints are eliminated, and the variable space is deduced to only non-basic variables. The process repeats again until it fulfills the optimal conditions [10]. In a general case mathematically the method can be written as [11]:

$$
\min f(x)
$$

subject to

$$
\begin{gathered}
g_{i}(X)=0, i=1, \ldots, m, \\
l_{i} \leq X_{i} \leq u_{i}, i=1, \ldots, n,
\end{gathered}
$$

where $X$ in $n$-vector;

$l_{i}, u_{i}$ - given upper and lower bounds, $u_{i}>l_{i}$.

To find the optimal proportion of wind and solar generation by implementing the GRG method the Microsoft Excel Solver was used [12]. Since the data for the simulation are represented in relative units, the following restrictions are imposed, and the formulation of the result can be written as:

$$
\begin{gathered}
P_{A i}=P_{w i} \cdot l_{i}+P_{s i} \cdot u_{i}, i=1, \ldots, n, \\
0 \leq l_{i} \leq 1, \\
0 \leq u_{i} \leq 1, \\
P_{A i} \leq 1,
\end{gathered}
$$

where $P_{A i}$-aggregated power from wind and solar sources for the period;

$P_{e i}$ - power from the wind source for the period;

$P_{s i}$ - power from the solar source for the period;

$n$ - number of periods.

Daily mean output

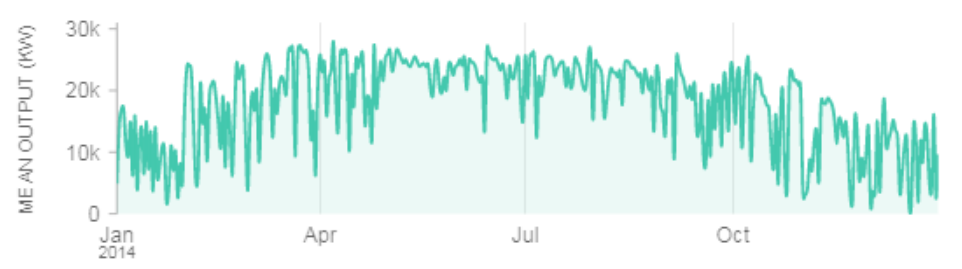

Monthly capacity factor

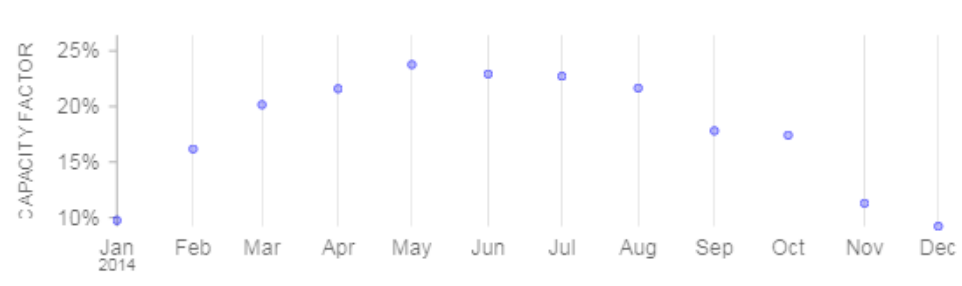

Total mean capacity factor: $17.9 \%$

Fig. 3. Renewables.ninja 100 MW PV solar plant power output profile simulation for 2014 
The network simulation scheme with RES and the energy storage are presented in Figure 4. Energy storage and the renewable energy sources are included in the simulation model as an addition to the existing network.

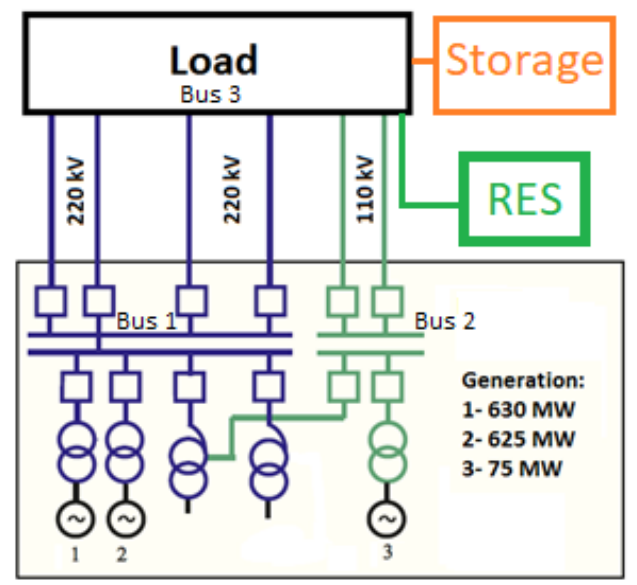

Fig. 4. Electrical scheme of modeling part of electrical grid with RES and energy storage

For the UC problem solution and network simulation the MATPOWER and MOST packages, working in the MATLAB environment with a GUROBI solver, were used to develop the modeling case of Kazakhstan's electrical network part [5].

\section{Results and discussion}

\subsection{Storage unit capacity simulation results}

Simulation was done for three combinations of renewable energy sources: wind, solar, aggregated (combination of wind and solar energy).

The results of calculations of the initial data for the electric power storage for each case of modeling with RES involvement are presented in Table 3.

Table 3

Input data of the energy storage unit simulation

\begin{tabular}{|c|c|c|c|}
\hline RES power, MW & $\boldsymbol{P}_{\boldsymbol{s}} \cdot \mathbf{1 . 2 5}$, wind & $\boldsymbol{P}_{\boldsymbol{s}} \cdot \mathbf{1 . 2 5}, \mathbf{P V}$ solar & $\boldsymbol{P}_{\boldsymbol{s}} \cdot \mathbf{1 . 2 5}$, aggregated \\
\hline 250 & 269 & 214 & 299 \\
\hline 297 & 319 & 255 & 356 \\
\hline 547 & 588 & 469 & 655 \\
\hline
\end{tabular}

\subsection{Renewable energy source types best combination calculation results}

According to the results of calculations, in order to achieve the installed capacity of the combined installation (aggregated generation) of a solar and wind power plant in $100 \%$, the share of each type of energy should be $100 \%$. This means that, say, to obtain a capacity of $100 \mathrm{MW}$, from the sun and wind at the same time, the installed capacity of $100 \mathrm{MW}$ of both a solar power plant and a wind power station is needed. The results of the calculation in relative units are represented in Table 4 and Fig. 5.

Table 4

12 months aggregated power generation profile from the wind and PV solar plant sources in the Mangistau region for the year 2014

\begin{tabular}{|c|c|c|c|c|c|c|c|c|c|c|c|c|}
\hline Months & $\mathbf{1}$ & $\mathbf{2}$ & $\mathbf{3}$ & $\mathbf{4}$ & $\mathbf{5}$ & $\mathbf{6}$ & $\mathbf{7}$ & $\mathbf{8}$ & $\mathbf{9}$ & $\mathbf{1 0}$ & $\mathbf{1 1}$ & $\mathbf{1 2}$ \\
\hline $\begin{array}{c}\text { Aggre- } \\
\text { gated, } \\
\text { relative } \\
\text { units }\end{array}$ & 0.3833 & 0.5139 & 0.5811 & 0.5626 & 0.5065 & 0.4838 & 0.3876 & 0.3944 & 0.4791 & 0.3885 & 0.4327 & 0.4701 \\
\hline
\end{tabular}




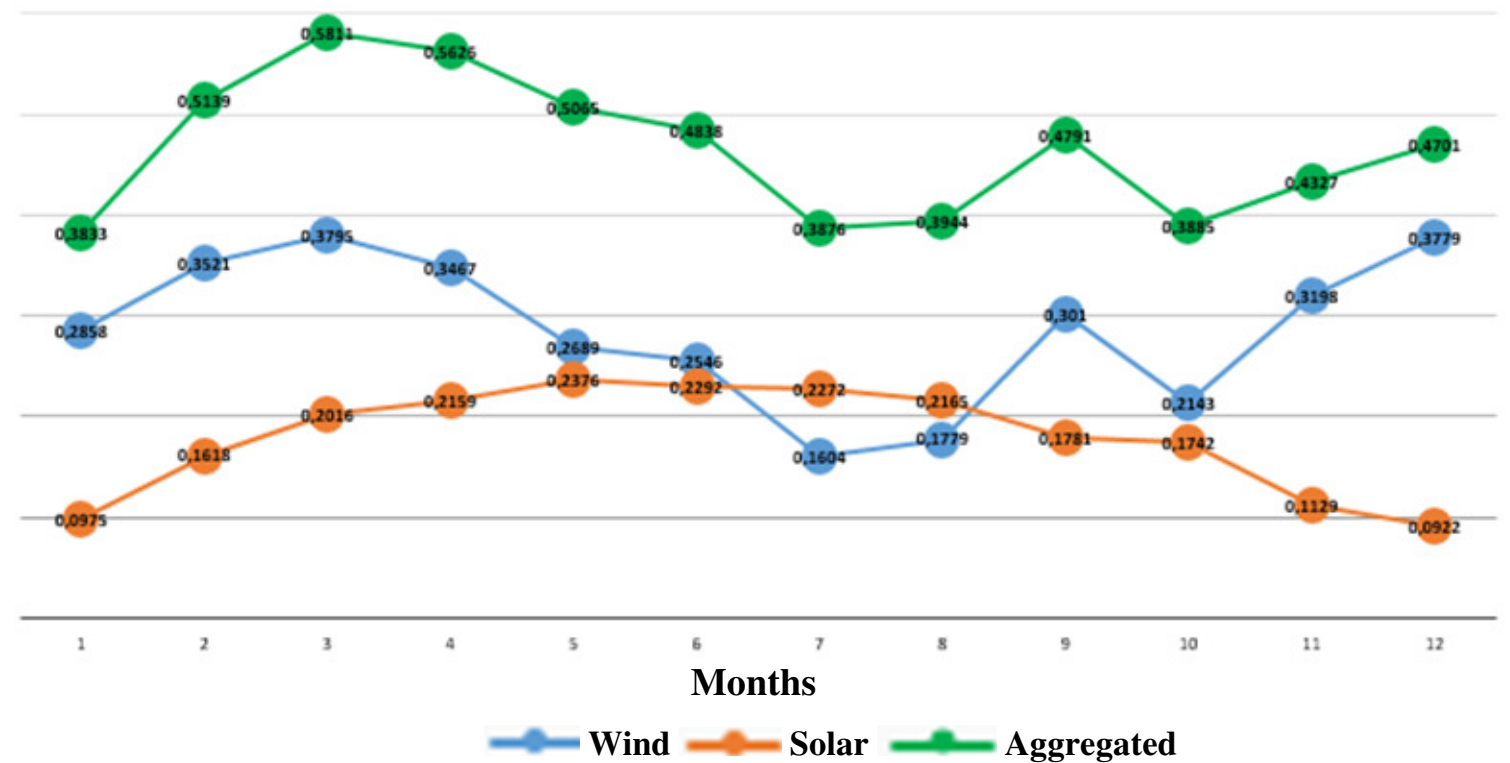

Fig. 5. 12 months aggregated power generation profile from wind and PV solar plant sources in Mangistau region for 2014. Source: authors' calculations

For the purpose of the UC simulation, daily power output profile from the aggregated power sources with the $100 \%$ of wind and solar capacities impact were calculated for the specified days (22.06.2014 - minimum power peak, 22.12.2014 - maximum power peak). The results of the calculation in relative units are represented in Tab. 5, 6 and Fig. 6, 7.

Table 5

24 hours aggregated power generation profile from the wind and PV solar plant sources in the Mangistau region on 22.06.2014

\begin{tabular}{|c|c|c|c|c|c|c|c|c|c|c|c|c|}
\hline Hours & $\mathbf{1}$ & $\mathbf{2}$ & $\mathbf{3}$ & $\mathbf{4}$ & $\mathbf{5}$ & $\mathbf{6}$ & $\mathbf{7}$ & $\mathbf{8}$ & $\mathbf{9}$ & $\mathbf{1 0}$ & $\mathbf{1 1}$ & $\mathbf{1 2}$ \\
\hline $\begin{array}{c}\text { Relative } \\
\text { units }\end{array}$ & 0.034 & 0.029 & 0.017 & 0.01 & 0.013 & 0.026 & 0.053 & 0.156 & 0.319 & 0.496 & 0.644 & 0.69 \\
\hline Hours & $\mathbf{1 3}$ & $\mathbf{1 4}$ & $\mathbf{1 5}$ & $\mathbf{1 6}$ & $\mathbf{1 7}$ & $\mathbf{1 8}$ & $\mathbf{1 9}$ & $\mathbf{2 0}$ & $\mathbf{2 1}$ & $\mathbf{2 2}$ & $\mathbf{2 3}$ & $\mathbf{2 4}$ \\
\hline $\begin{array}{c}\text { Relative } \\
\text { units }\end{array}$ & 0.716 & 0.793 & 0.892 & 0.894 & 0.793 & 0.719 & 0.66 & 0.638 & 0.628 & 0.609 & 0.596 & 0.641 \\
\hline
\end{tabular}




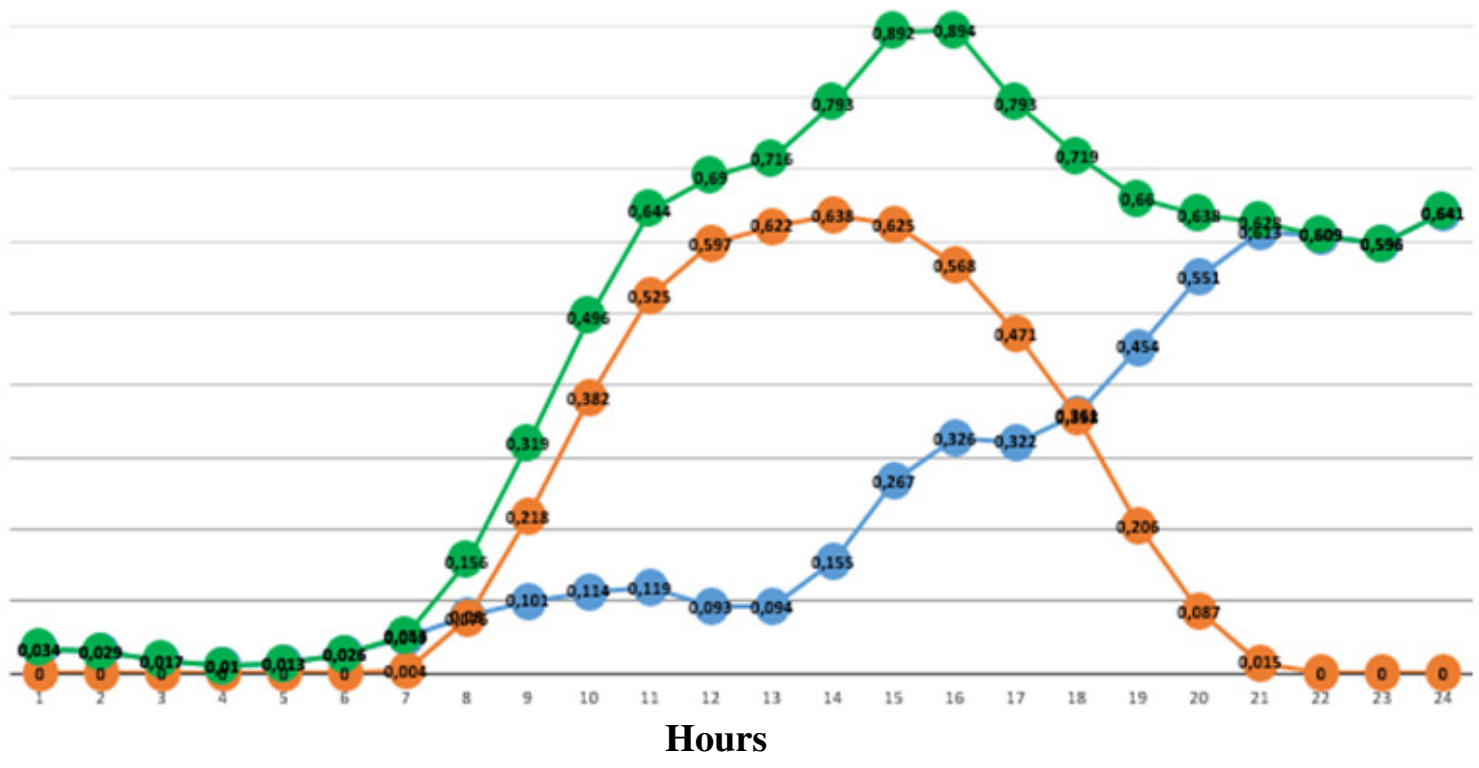

$\sim$ Wind - Solar - Aggregated

Fig. 6. 24 hours aggregated power generation profile from wind and PV solar plant sources in Mangistau region on 22.06.2014. Source: authors' calculations

Table 6

24 hours aggregated power generation profile from the wind and PV solar plant sources in the Mangistau region on 22.12.2014

\begin{tabular}{|c|c|c|c|c|c|c|c|c|c|c|c|c|}
\hline Hours & $\mathbf{1}$ & $\mathbf{2}$ & $\mathbf{3}$ & $\mathbf{4}$ & $\mathbf{5}$ & $\mathbf{6}$ & $\mathbf{7}$ & $\mathbf{8}$ & $\mathbf{9}$ & $\mathbf{1 0}$ & $\mathbf{1 1}$ & $\mathbf{1 2}$ \\
\hline $\begin{array}{c}\text { Relative } \\
\text { units }\end{array}$ & 0.445 & 0.502 & 0.545 & 0.58 & 0.66 & 0.632 & 0.66 & 0.686 & 0.718 & 0.759 & 0.818 & 0.887 \\
\hline Hours & $\mathbf{1 3}$ & $\mathbf{1 4}$ & $\mathbf{1 5}$ & $\mathbf{1 6}$ & $\mathbf{1 7}$ & $\mathbf{1 8}$ & $\mathbf{1 9}$ & $\mathbf{2 0}$ & $\mathbf{2 1}$ & $\mathbf{2 2}$ & $\mathbf{2 3}$ & $\mathbf{2 4}$ \\
\hline $\begin{array}{c}\text { Relative } \\
\text { units }\end{array}$ & 0.953 & 0.968 & 0.926 & 0.864 & 0.801 & 0.716 & 0.652 & 0.602 & 0.404 & 0.221 & 0.295 & 0.531 \\
\hline
\end{tabular}
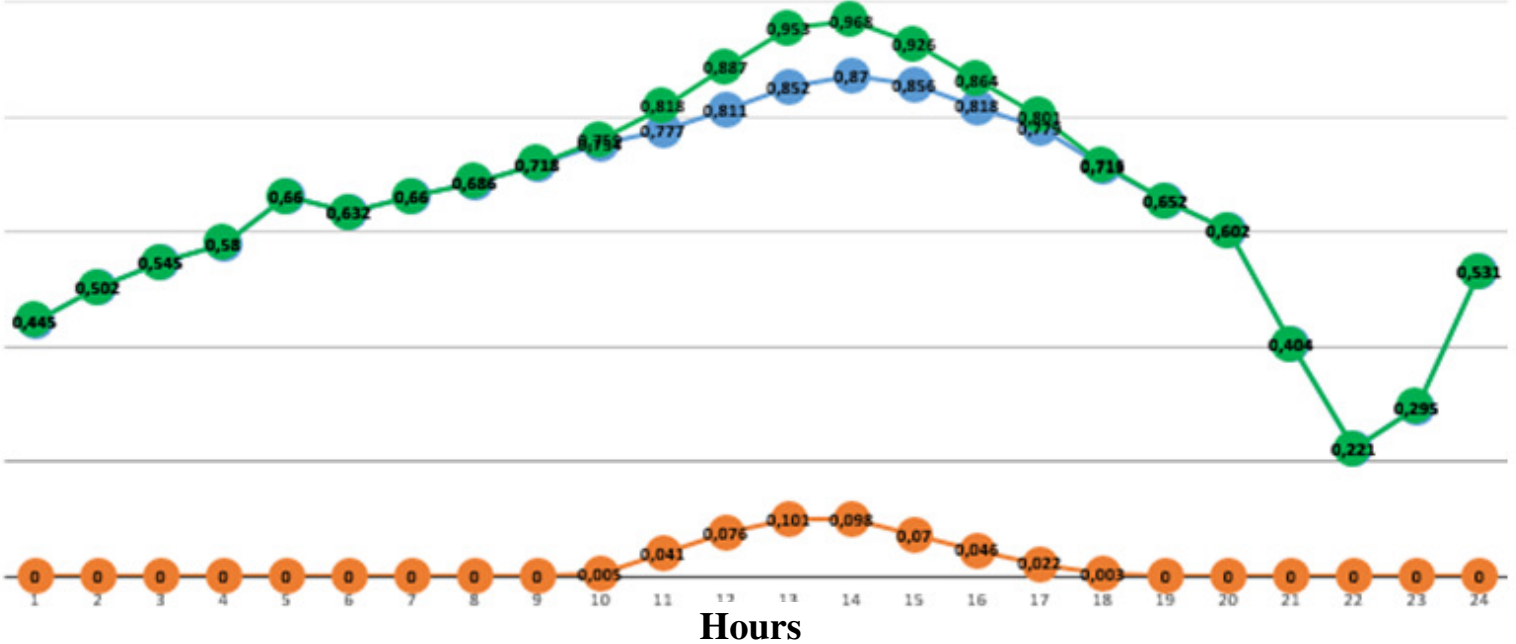

$\longrightarrow$ Wind $\longrightarrow$ Solar $\longrightarrow$ Aggregated

Fig. 7. 24 hours aggregated power generation profile from wind and PV solar plant sources in Mangistau region on 22.12.2014. Source: authors' calculations 


\subsection{UC simulation example with different constraints}

Here is represented a simulation example with the most loaded period (12.12.2014) as the most critical for the case study. The simulation results for the case with RES aggregated $250 \mathrm{MW}$, storage capacity 299 MW, load region - Mangistau on 22.12.2014 are represented in Table 7 and Figure 8.

Table 7

24 hours power generation profile for the case with RES aggregated $250 \mathrm{MW}$, storage capacity 299 MW, load region - Mangistau on 22.12.2014

\begin{tabular}{|c|c|c|c|c|c|c|c|c|c|c|c|c|}
\hline Hours & $\mathbf{1}$ & $\mathbf{2}$ & $\mathbf{3}$ & $\mathbf{4}$ & $\mathbf{5}$ & $\mathbf{6}$ & $\mathbf{7}$ & $\mathbf{8}$ & $\mathbf{9}$ & $\mathbf{1 0}$ & $\mathbf{1 1}$ & $\mathbf{1 2}$ \\
\hline $\begin{array}{c}\text { Gen 1, } \\
\text { MW }\end{array}$ & 445 & 445 & 445 & 445 & 445 & 445 & 410 & 343.5 & 320.65 & 320.65 & 320.65 & 320.65 \\
\hline $\begin{array}{c}\text { Gen 2, } \\
\text { MW }\end{array}$ & 0 & 0 & 0 & 0 & 0 & 0 & 0 & 0 & 0 & 0 & 0 & 0 \\
\hline $\begin{array}{c}\text { Gen 3, } \\
\text { MW }\end{array}$ & 72 & 72 & 72 & 72 & 72 & 72 & 72 & 72 & 72 & 72 & 72 & 72 \\
\hline $\begin{array}{c}\text { Storage } \\
\text { charge (-) } \\
\text { /discharge } \\
(+)\end{array}$ & 52.75 & 28.5 & 12.75 & 19 & -1 & 1 & 0 & 0 & -0.15 & -6.4 & -17.15 & -40.4 \\
\hline $\begin{array}{c}\text { Excess (-) } \\
\text { /Deficit } \\
(+)\end{array}$ & 0.00 & 0.00 & 0.00 & 0.00 & 0.00 & 0.00 & 0.00 & 0.00 & 0.00 & 0.00 & 0.00 & 0.00 \\
\hline Hours & $\mathbf{1 3}$ & $\mathbf{1 4}$ & $\mathbf{1 5}$ & $\mathbf{1 6}$ & $\mathbf{1 7}$ & $\mathbf{1 8}$ & $\mathbf{1 9}$ & $\mathbf{2 0}$ & $\mathbf{2 1}$ & $\mathbf{2 2}$ & $\mathbf{2 3}$ & $\mathbf{2 4}$ \\
\hline $\begin{array}{c}\text { Gen 1, } \\
\text { MW }\end{array}$ & 320.65 & 320.65 & 320.65 & 320.65 & 320.65 & 320.65 & 336 & 407.1 & 448.6 & 454.35 & 454.35 & 425.35 \\
\hline $\begin{array}{c}\text { Gen 2, } \\
\text { MW }\end{array}$ & 0 & 0 & 0 & 0 & 0 & 0 & 0 & 0 & 0 & 0 & 0 & 0 \\
\hline $\begin{array}{c}\text { Gen 3, } \\
\text { MW }\end{array}$ & 72 & 72 & 72 & 72 & 72 & 72 & 72 & 72 & 72 & 72 & 72 & 72 \\
\hline $\begin{array}{c}\text { Storage } \\
\text { charge (-) } \\
\text { /discharge } \\
\text { (+) }\end{array}$ & -54.9 & -62.65 & -46.15 & -39.65 & -21.9 & -9.65 & 0 & 1.4 & 41.4 & 81.4 & 50.9 & 10.9 \\
\hline $\begin{array}{c}\text { Excess (-) } \\
\text { /Deficit } \\
(+)\end{array}$ & 0.00 & 0.00 & 0.00 & 0.00 & 0.00 & 0.00 & 0.00 & 0.00 & 0.00 & 0.00 & 0.00 & 0.00 \\
\hline
\end{tabular}

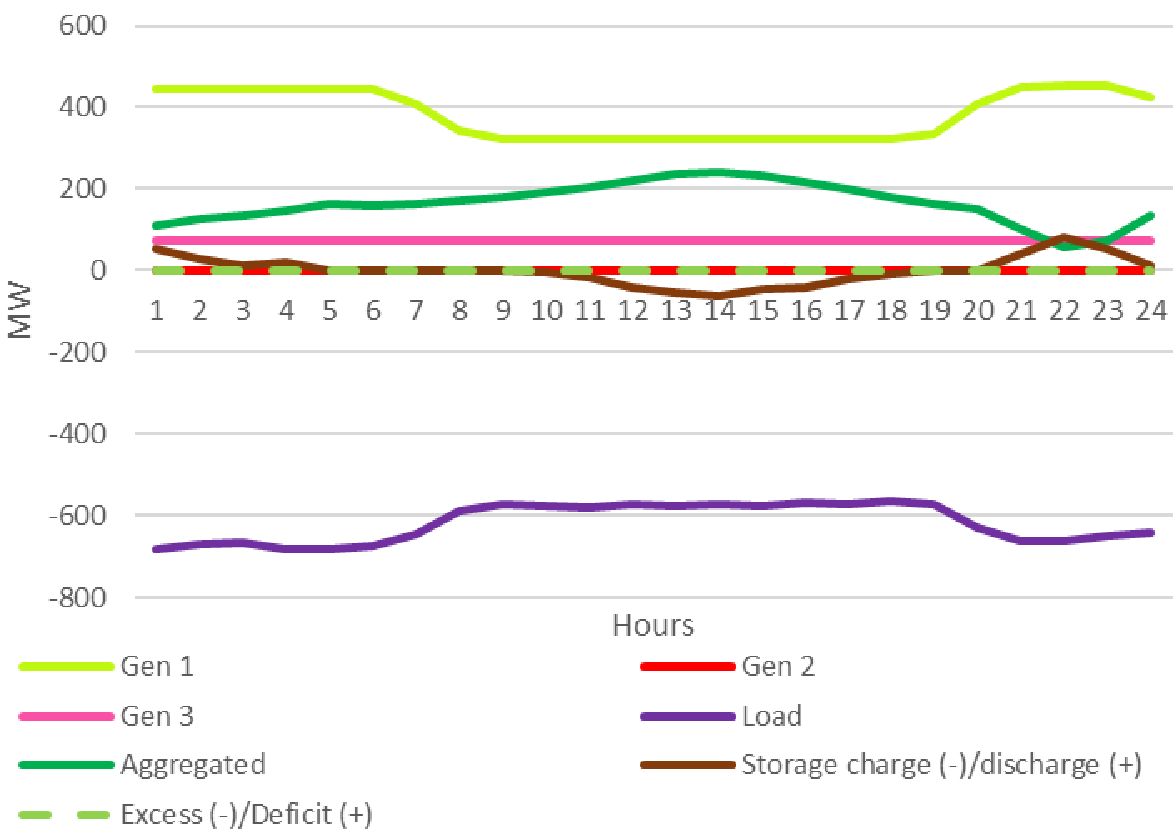




\section{Fig. 8. 24 hours power generation profile for case with RES aggregated $250 \mathrm{MW}$, storage} capacity 299 MW, load region - Mangistau on 22.12.2014. Source: authors' calculations

\section{Conclusions}

Analysing the results of the simulation of the rural part of the electrical network with the energy storage and the renewables the following conclusions can be made:

1. The most optimal it is to use a combination of wind and solar energy for the region;

2. The use of power storage devices allows to make part of the system autonomous (the value 0 -in Excess (-)/Deficit ( + ) row, Table 7);

3. The outlined trend of reducing the cost of the power storage devices will significantly expand their range of applications.

The presence of electricity storage allows smoothing the peaks of power generation and consumption, which can reach 81.4 megawatts in absolute terms. In addition, the usage of energy storage facilities allows to bring the generator 2 out of work.

This study shows the technical feasibility of autonomous operation of the system with power storage devices. To study the economic feasibility of the introduction of power storage devices in combination with renewable energy sources, it is necessary to conduct a comparative economic analysis of options for creating a transmission line to the object, or using traditional energy sources.

\section{References}

[1] Stoyak V.V., Zavadskiy V.A., Kumyzbayeva S.K., Intellectual management of distributed generation - Virtual heat power plants: the new generation energy systems. Vestnik AUES. №4(43).- 2018. pp. 28-37.

[2] Petersen M.K., Hansen L.H., Bendtsen J., Edlund K., Stoustrup J. Market Integration of Virtual Power Plants; IEEE: New York, NY, USA, 2013; pp. 2319-2325.

[3] Dabbagh S.R., Sheikh-El-Eslami M.K. Risk-based profit allocation to DERs integrated with a virtual power plant using cooperative Game theory. Electr. Power Syst. Res. 2015, 121, pp. 368-378.

[4] Ehsan A., Yang Q. Optimal integration and planning of renewable distributed generation in the power distribution networks: A review of analytical techniques. Appl. Energy 2018, 210, pp. 44-59.

[5] Zavadskiy V., Revalde G. Involving renewable Energy sources in generating process: the example of Kazakhstan, Engineering For Rural Development, Jelgava, 23.-25.05.2018, DOI: 10.22616/ERDev2018.17.N547, pp. 1939-1947

[6] Schroeder A., Siegmeier J., Creusen M., Modeling Storage and Demand Management in Electricity Distribution Grids, Deutsches Institut für Wirtschaftsforschung, Berlin, 2011.

[7] Eller A., Gauntlett D., Energy Storage Trends and Opportunities in Emerging Markets, Conference edition, 2017. [online][01.08.2017] Available at: https://www.ifc.org/wps/ $\mathrm{wcm} /$ connect/ed6f9f7f-f197-4915-8ab6-56b92d50865d/7151-IFC-EnergyStorage-report. pdf?MOD = AJPERES

[8] Spector J., Storage Costs Come Down Across Technologies and Applications According to Lazard Report. But a great deal of cost variance persists among those different uses, "Greentech Media", 2016. [online][15.08.2017] Available at: https://www.greentech media.com/articles/ read/energy-storage-costs-lcos-lazard-lithium-ion-flow-batteries\#gs.Pt22Das

[9] Renewables.ninja RES power output forecasting tool. [online][ 16.07.2017] Available at: https://www.renewables.ninja/

[10]Hong-Tau Lee, Sheu-Hua Chen, He-Yau Kang, A Study of Generalized Reduced Gradient Method with Different Search Directions, Department of Industrial Engineering and Management National Chin-Yi Institute of Technology, Taichung, Taiwan, Department of Industrial Engineering and Management Hsiou-ping Institute of Technology Taichung, Taiwan, 2004.

[11]Lasdon L. S., Fox R. L., Ratner M. W., Nonlinear optimization using the generalized reduced gradient method, AFCET, 1974.

[12] McFedries P., Formulas and Functions: Microsoft Excel 2010, Pearson Education, Inc., 2010. 